\title{
Facing Complexity in Systems Management
}

\author{
Metin Feridun \\ IBM Research — Zurich \\ Säumerstrasse 4 \\ $\mathrm{CH}-8803$ Rüschlikon, Switzerland \\ fer@zurich.ibm.com
}

\begin{abstract}
Emerging technologies such as cloud computing, increased use, proliferation and mobility of powerful end-user devices, and the migration of applications to the Internet, are creating new and exciting challenges to the management of IT (Information Technology) infrastructures. Massive scale and distribution of IT resources, the expectation of high availability of Internetbased services, and heterogeneity of resources are prominent examples of complexity system administrators encounter today. New approaches are needed for these new (and in many cases old) problems.

This keynote will survey some of these systems management issues and the emerging approaches to solving them.
\end{abstract}

